\title{
Sugarcane bagasse gasification in a downdraft fixed-bed gasifier: Optimization of operation conditions
}

\author{
Reza Jahromi ${ }^{1}$, Mahdi Rezaei ${ }^{*}$, Seyed Hashem Samadi ${ }^{3}$ \\ ${ }^{1}$ Department of Biomedical Engineering, Texas A\&M University, College Station, TX 77843, USA \\ reza.jahromi@tamu.edu \\ 2 Department of Mechanical Engineering, Shahid Rajaee University, Tehran, Iran \\ rezaei.mahdi78@gmail.com \\ ${ }^{3}$ Department of Mechanics of Biosystem Engineering, Tarbiat Modares University, Tehran, Iran \\ h.samadi1987@gmail.com \\ * Corresponding author. Tell. : +98-21-88364604; Email address: rezaei.mahdi78@gmail.com
}

\begin{abstract}
Herein, a CFD model for the gasification of sugarcane bagasse in a downdraft fixed-bed gasifier has been developed. Our objective was to observe syngas yield distribution in different operation conditions and to obtain optimal parameters. Several factors were investigated, including the velocity and preheating temperature of inlet air-steam mixture, steam to air ratio (S/A), and biomass moisture content (MC). Our results proposed that increasing S/A up to about 0.67 would be favorable and result in higher amounts of syngas yield and conversion efficiency, while an excessive increase in S/A had adverse effects. Both small and large amounts of air-steam inlet velocity were unfavorable, and optimal velocity was obtained at a median amount $(20 \mathrm{~m} / \mathrm{s})$. Increasing the preheating temperature of the oxidizing agent and also decreasing the $\mathrm{MC}$ of sugarcane bagasse had positive impacts on the gasification process. Finally, the maximum conversion efficiency was obtained equal to $69.14 \%$ for optimum operating conditions.
\end{abstract}

Keywords: biomass gasification; downdraft fixed-bed gasifier; computational fluid dynamics (CFD); sugarcane bagasse; optimization 


\section{Introduction}

Energy production is one of the most important economic factors in the development of modern society. Even now, despite the passage of years, energy demand and supply are heavily dependent on fossil fuels. With regard to the problems related to environmental issues, fluctuations in fossil revenues, and growing demand for energy in the modern world, statesmen and politicians have encouraged in the use of other non-fossil energy, especially renewable resources [1-4]. Thus, the production of renewable fuels can potentially play a critical role in the fate of next-generation energy. Considering the limited supplies of traditional fossil fuels, lignocellulosic biomass is the most abundant source of renewable carbon that does not interfere with global warming [5-7]. Therefore, the development of new technologies that incorporate biomass in the production of renewable energy can possibly be one of the most feasible pathways to cover future needs for fuels and chemicals [8-15].

Gasification is one of the promising technologies for using biomass to produce fuel and energy. Gasification is the degradation of biomass by reacting the material at high temperatures $\left(>700{ }^{\circ} \mathrm{C}\right)$ with a controlled amount of oxidizing agent (air, oxygen or/and steam), which results in the production of carbon monoxide, hydrogen, methane and carbon dioxide [16]. Many methods have been developed for modeling the gasification process in downdraft and updraft gasifiers. The proposed models of biomass gasification include thermodynamic equilibrium, kinetic, computational fluid dynamics (CFD), artificial neural network (ANN), and ASPEN Plus models [17-22].

Thermodynamic equilibrium (zero-dimensional) models have been widely used by researchers [23-27]. Sharma [26] performed a full equilibrium model of reduction reactions to predict the distribution of gas species and unconverted char. Considering Douglas fir bark as feedstock, he concluded that the range of moisture content and equivalence ratio should be limited to $10-20 \%$ and 0.3-0.45, respectively. Huang et al. [23] developed thermodynamic equilibrium models for various gasifier types with and without considering char. The zero-dimensional model is only used for determining the equilibrium temperature and mixture of products. This model is independent of geometry. Velocities and temperature profiles would not be obtained from this model due to neglecting transformation mechanisms. In kinetic (non-equilibrium) models, reaction kinetics and transformation equations of mass, momentum, energy, and species are considered. Some researchers have simulated the gasification reactor in one-dimensional (1D) models [28-31], in which movements are assumed vertically uniform. Chaurasia [32] coupled a downdraft gasifier model with a singleparticle model to examine the particle geometry effects on different parameters. He found that the sensitivity for all the studied parameters was the highest for the spherical geometry and lowest for the slab geometry. Some others have simulated CFD models for updraft and downdraft gasifiers in twodimension to develop the gasification process [33-37]. Wu et al. [35] used CFD to simulate the gasification process, considering the reactions of drying, pyrolysis, and combustion. They concluded that an external heat source is required in the gasifier for a high-temperature gasification system. Fernando et al. [34] simulated a moving bed updraft biomass gasifier using CFD. They obtained a specific air flow rate to maximize the $\mathrm{CO}$ production rate for a specific laboratory gasifier. Bogdanova et al. [33] simulated a fluidized bed gasifier to represent particle/particles and fluid/particles interactions, and defined optimal operating conditions for an industrial scale gasifier. 
Currently, about 1,800,000 tons of sugarcane bagasse is produced in Iran. This agricultural waste is rarely used in livestock, paper, and wood industries and also does not compete with the food stream. Therefore, by using proper gasification technology in recycling sugarcane bagasse, in addition to protecting the environment and creating income opportunities, it can meet some of the energy needs [38]. A few studies have been developed for the gasification of sugarcane bagasse as an abundant feedstock. In addition, the need for investigation of cross-interaction between different operating conditions (i.e., inlet velocity and temperature of the oxidizing agent, steam to air ratio, and feedstock moisture content) must receive critical attention. Herein, to the best of our knowledge, we have developed a CFD model of a downdraft fixed-bed gasifier for sugarcane bagasse gasification process, and we have investigated the simultaneous influences of several operating parameters on the final product distribution, in hopes of being useful to the engineers who want to make use of sugarcane bagasse. The reconstructed geometry was based on the geometry of a $20 \mathrm{~kW}$ commercial system from GEK, produced by ALL Power Labs (USA) [39]. Several design parameters were simultaneously investigated, including the preheating temperature and the inlet velocity of the oxidizing agent, steam to air ratio, and the moisture content of biomass. Our main objective was to observe the distribution of syngas yield in different operating conditions and to determine the optimal operating parameters for maximizing the syngas yield and conversion efficiency of sugarcane bagasse gasification.

\section{Methods}

In the present study, a downdraft fixed-bed gasification reactor was simulated two-dimensionally using the Eulerian method. By considering two-dimensional modeling, the effects of the reactor geometry and gasification properties can be investigated along vertical and horizontal directions. Fluid flow was assumed to be steady [40-42] and turbulent [42-45] similar to previous studies. Feedstock entered the reactor from the upper part of the geometry, and air inlet nozzles were located on both sides of the reactor. Outlet syngas were discharged from the bottom of the reactor. Mass, momentum, and energy equations were solved using the first-order upwind scheme. Species transport was solved by the Eddy dissipation method. Radiant heat transfer was significant because of the high temperature of the reactor; thus P1 model was used for this type of heat transfer, similar to the literature [46].

\subsection{Fuel properties and reactions}

Bagasse pellets initially have a moisture content of more than $50 \%$. This moisture should be reduced by pre-drying. Bagasse with higher moisture content requires more energy to begin the gasification process; therefore, pre-drying and decreasing the moisture content of bagasse is necessary. In the present study, sugarcane bagasse properties were introduced to ANSYS Fluent 16.2, defined by proximate and ultimate analyses. Different properties are reported for different types of woods in the literature. The properties used in the present study are shown in Table 1. 
Table 1 Proximate and ultimate analyses of sugarcane bagasse [47]

\begin{tabular}{cc}
\hline & Sugarcane bagasse \\
\hline Moisture content & $1.14 \%$ \\
Volatile matter content & $69.99 \%$ \\
Fixed carbon & $16.39 \%$ \\
Ash & $1.42 \%$ \\
Nitrogen $(\mathrm{N})$ & $0.20 \%$ \\
Carbon $(\mathrm{C})$ & $44.1 \%$ \\
Hydrogen $(\mathrm{H})$ & $5.7 \%$ \\
Sulfur $(\mathrm{S})$ & $2.3 \%$ \\
Oxygen $(\mathrm{O})$ & $47.7 \%$ \\
\hline
\end{tabular}

Biomass is composed of carbon, oxygen, hydrogen, sulfur and nitrogen. After dehydration, biomass undergoes oxidation and reduction reactions during gasification process. These chemical reactions are listed in the following [48].

$$
\begin{aligned}
& 2 \mathrm{C}+\mathrm{O}_{2} \rightarrow 2 \mathrm{CO} \quad \text { (partial oxidation) } \\
& \mathrm{C}+\mathrm{O}_{2} \rightarrow 2 \mathrm{CO}_{2} \quad \text { (complete oxidation) } \\
& \mathrm{C}+2 \mathrm{H}_{2} \rightarrow \mathrm{CH}_{4} \quad \text { (hydrogasification reaction) } \\
& \mathrm{CnHm}+\mathrm{n} \mathrm{H2O} \rightleftarrows(\mathrm{n}+\mathrm{m} / 2) \mathrm{H} 2+\mathrm{n} \mathrm{CO} \quad \text { (steam reforming reaction) } \\
& \mathrm{CO}+3 \mathrm{H}_{2} \rightleftarrows \mathrm{CH}_{4}+\mathrm{H}_{2} \mathrm{O} \quad \text { (Methanation) } \\
& \mathrm{CO}+\mathrm{H}_{2} \mathrm{O} \rightleftarrows \mathrm{CO}_{2}+\mathrm{H}_{2} \quad \text { (water }- \text { gas shift reaction) } \\
& \mathrm{C}+\mathrm{H}_{2} \mathrm{O} \rightarrow \mathrm{CO}+\mathrm{H}_{2} \quad \text { (carbon conversion to gas) } \\
& \mathrm{C}+\mathrm{CO}_{2} \rightleftarrows 2 \mathrm{CO} \quad \text { (Boudouard reaction) }
\end{aligned}
$$

Carbon monoxide and carbon dioxide are obtained from carbon partial and complete combustions respectively, shown in Eq. (1) and (2). Eq. (3) and (5) show the production of methane gas. In steam reforming reaction, non-methane hydrocarbons of low quality gases are converted to synthesis gas $(\mathrm{H} 2+\mathrm{CO})$ shown in Eq. (4), and finally to methane, carbon dioxide and hydrogen, shown in Eq. (5) and (6), thereby improving the fuel gas quality. Eq. (7) shows the production of synthetic fuels from carbon and steam reaction. Boudouard reaction, shown in Eq. (9), is the redox reaction of chemical equilibrium mixture of carbon dioxide and carbon monoxide. This reaction to form carbon dioxide and carbon is exothermic at all temperatures. As our main objective was to observe the distribution of outlet syngas and conversion efficiency of the reactor in different operating conditions, tar formation reactions were neglected, because final tar is formed in small amount and has little impact on syngas yield [49]. 


\subsection{Governing equations}

Mass, momentum and energy equations are described as follows:

$\nabla .(\rho \vec{v})=S_{m}$

$\nabla \cdot(\rho \overrightarrow{\mathrm{v}} \overrightarrow{\mathrm{v}})=-\nabla \mathrm{p}+\nabla \cdot(\overline{\bar{\tau}})+\rho \overrightarrow{\mathrm{g}}+\overrightarrow{\mathrm{F}}$

$\frac{\partial}{\partial \mathrm{x}_{\mathrm{i}}}\left(\rho \overline{\mathrm{u}}_{\mathrm{i}} \mathrm{h}\right)=\frac{\partial}{\partial \mathrm{x}_{\mathrm{i}}}\left(\mathrm{k} \frac{\partial \mathrm{T}}{\partial \mathrm{x}_{\mathrm{i}}}\right)+\mathrm{S}_{\mathrm{ph}}$

In eq. (9), the term $S_{m}$ includes the added mass resulted from evaporation of water droplets, and the conversion of charcoal particles into volatile gases, which are added from the secondary phase to the continuous phase. In eq. (10), p is the static pressure, $\overline{\bar{\tau}}$ is the stress tensor, and the vectors $\rho \overrightarrow{\mathrm{g}}$ and $\overrightarrow{\mathrm{F}}$ are the gravity and external body forces (resulted from the interaction between phases), respectively. In eq. (11), the second term of the right side is the source term for the transfer of heat from gas particles, evaporation energy (latent heat), radiation energy, and reaction heat. The stress tensor $\overline{\bar{\tau}}$ is expressed as follows:

$\overline{\bar{\tau}}=\mu\left[\nabla \vec{v}+\nabla \vec{v}^{T}\right]-\frac{2}{3} \nabla \cdot \vec{v} I$

Where $\mu$ is the molecular viscosity, I is the unit tensor, and the third term on the right side of the equation is the effect of volume expansion.

\subsection{Turbulence model}

The kinetic turbulence energy, $\mathrm{k}$, and its dissipation rate, $\varepsilon$, are obtained from the following $\mathrm{k}-\varepsilon$ equations:

$\frac{\partial}{\partial \mathrm{x}_{\mathrm{i}}}\left(\rho \mathrm{ku}_{\mathrm{i}}\right)=\frac{\partial}{\partial \mathrm{x}_{\mathrm{j}}}\left[\left(\mu+\frac{\mu_{\mathrm{t}}}{\sigma_{\mathrm{k}}}\right) \frac{\partial \mathrm{k}}{\partial \mathrm{x}_{\mathrm{j}}}\right]+\mathrm{G}_{\mathrm{k}}-\rho \varepsilon$

$\frac{\partial}{\partial \mathrm{x}_{\mathrm{i}}}\left(\rho \varepsilon \mathrm{u}_{\mathrm{i}}\right)=\frac{\partial}{\partial \mathrm{x}_{\mathrm{j}}}\left[\left(\mu+\frac{\mu_{\mathrm{t}}}{\sigma_{\varepsilon}}\right) \frac{\partial \varepsilon}{\partial \mathrm{x}_{\mathrm{j}}}\right]+\mathrm{C}_{1 \varepsilon} \frac{\varepsilon}{\mathrm{k}} \mathrm{G}_{\mathrm{k}}-\mathrm{C}_{2 \varepsilon} \rho \frac{\varepsilon^{2}}{\mathrm{k}}$

Where $\mathrm{G}_{\mathrm{k}}$ represents the production of kinetic turbulence energy. It is related to the mean velocity gradient. $\sigma_{\mathrm{k}}$ and $\sigma_{\varepsilon}$ are the turbulent Prandtl numbers for $\mathrm{k}$ and $\varepsilon$, respectively. Turbulence viscosity (or eddy), $\mu_{\mathrm{t}}$, is obtained from the combination $\mathrm{k}$ and $\varepsilon$ :

$\mu_{\mathrm{t}}=\rho \mathrm{C}_{\mu} \frac{\mathrm{k}^{2}}{\varepsilon}$

The constants of the experimental model are equal to $\mathrm{C}_{1 \varepsilon}=1.44, \mathrm{C}_{2 \varepsilon}=1.92, \mathrm{C}_{\mu}=0.09, \sigma_{\mathrm{k}}=1.0$ and $\sigma_{\varepsilon}=1.3[50]$.

\subsection{Conversion efficiency}

Gas heating value is calculated from the following equation. Volume concentrations of the outlet syngas are used in this equation. 


$$
\mathrm{HV}_{\text {gas }}=\left(\frac{\left(\mathrm{CO}_{\mathrm{vol}}\right)(\mathrm{HVCO})+\left(\mathrm{H}_{2 \mathrm{vol}}\right)\left(\mathrm{HVH}_{2}\right)+\left(\mathrm{CH}_{4} \mathrm{vol}\right)\left(\mathrm{HVCH}_{4}\right)}{100 \%}\right)
$$

Where $\mathrm{CO}_{\mathrm{vol}}, \mathrm{H}_{2 \mathrm{vol}}$ and $\mathrm{CH}_{4 \mathrm{vol}}$ are molar concentrations of carbon monoxide, hydrogen and methane gases, respectively. Heating values of these gases are: $\mathrm{HVCO}=12.64 \mathrm{MJ} \mathrm{kg}^{-1}$ [51], $\mathrm{HVH}_{2}=$ $10.1 \mathrm{MJ} \mathrm{kg}^{-1}$ [52] and $\mathrm{HVCH}_{4}=38 \mathrm{MJ} \mathrm{kg}^{-1}$ [51].

The energy conversion efficiency of the gasification process is calculated by the following equation [53]:

$\eta=100\left(\frac{2 \mathrm{HV}_{\text {gas }}}{\mathrm{HV}_{\text {fuel }}}\right)$

Where $\mathrm{HV}_{\text {fuel }}$ is the heating value of sugarcane bagasse. Various heating values have been reported from 17.8 to $19.5 \mathrm{MJ} \mathrm{kg}^{-1}$ for bagasse. In the present study, the heating value of sugarcane bagasse was assumed to be $19 \mathrm{MJ} \mathrm{kg}^{-1}$ according to the value obtained by Paramour et al. [54]. The equivalent ratio was considered to be constant for all simulations here.

\subsection{Geometry reconstruction}

The geometry of a $20 \mathrm{~kW}$ commercial system from GEK ALL Power Labs [39] was used in the present simulation. This geometry was developed in SOLIDWORKS 2014. Mesh was generated in ANSYS Meshing 16.2 software. Feedstock entered the reactor from the upper part, which had a diameter of $182 \mathrm{~mm}$. Air inlet nozzles were assumed to be on both sides of the reactor, with a diameter of $9 \mathrm{~mm}$. For further explanation, drying reactions occur in the upper zone due to high temperature, and thereby the moisture of the feedstock evaporates immediately. Then, pyrolysis reactions occur in the next zone. Tar, coal, and volatile substances are obtained in this region. Finally, a series of oxidation and reduction reactions are performed. Figure 1 shows the inlets, outlet, and the sizes used in the reconstructed geometry of the simulated gasifier reactor. Separate zones of the geometry were merely for applying temperature in different regions and were not real areas of separation. The boundaries between different zones of the geometry were assumed to be bonded. They were factually virtual bonds and did not have any effect on the results. 


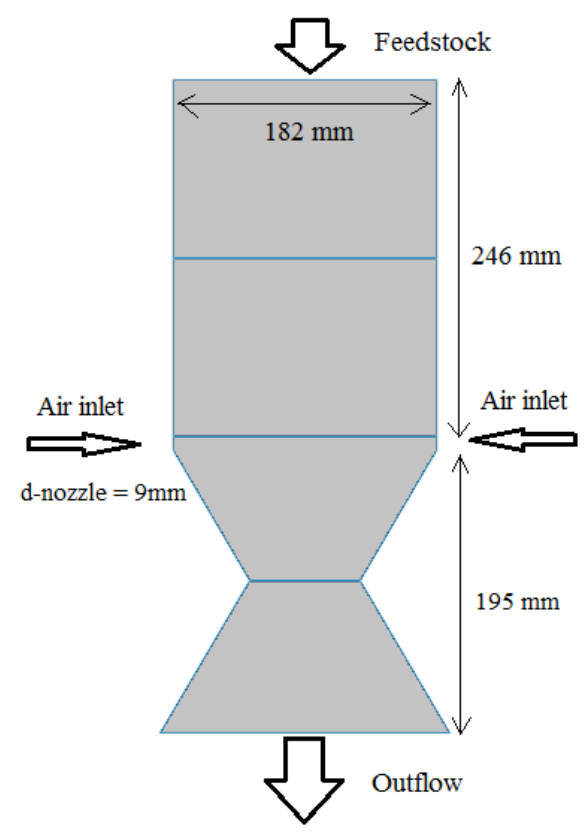

Figure 1. The reconstructed geometry of the simulated gasifier reactor

\subsection{Boundary conditions}

Similar to previous studies $[34,42,43,46]$, the inlet boundary condition of air-steam mixture was given by velocity inlet, varied from 5 to $40 \mathrm{~m} / \mathrm{s}$ (with $5 \mathrm{~m} / \mathrm{s}$ increment in each simulation), and the effect of this parameter was investigated on the mole fraction of outlet syngas. The inlet air nozzle was horizontally constructed, without any angle. Entering from these nozzles, the steam-to-air ratio was changed from $11 \%$ to $100 \%$, and the effect of this mixture percentage was studied. Feedstock entered the reactor from the upper part (as shown in Figure 1). It was given to software according to the proximal and ultimate analyses shown in Table 1. The pressure outlet boundary condition was assumed to be $1 \mathrm{~atm}$ (101325 Pascal) at the bottom of the reactor. The Pressure-velocity field was solved by the coupled method. The discrete spatial gradient and pressure gradient were solved by the least-squares cell-based (LSCB) and PRESTO methods, respectively. Conservation equations, turbulence, and species transport were solved by the first upwind method.

\subsection{Grid study and mesh generation}

Grid study was performed for the geometry of the reactor to reach mesh independence by using ANSYS Meshing 16.2. Air inlet velocity was assumed to be $30 \mathrm{~m} / \mathrm{s}$. Preheating temperature and S/A were $1300 \mathrm{~K}$ and 0.67 , respectively. A computer simulation was performed on half of the geometry due to the symmetry. CFD reference and fluent solver were used for mesh generation. Considering minimum, maximum and average values, the mean size of elements was reduced from 1.75 to 0.25 $\mathrm{mm}$, with $0.25 \mathrm{~mm}$ reduction in each step, in the form of a multizone quadrilateral/triangle. The number of cells obtained for the whole geometry (from larger to smaller cell size) was 32726, 46706, 72956, 95128, 128636, 185812, and 293196 cells, respectively. Investigated parameter for studying 
grid independence was the mole fraction of outlet syngas, including $\mathrm{CO}, \mathrm{H}_{2}$ and $\mathrm{CH}_{4}$. Figure 2a shows the mole fraction of outlet syngas when the number of cells was increased. It was observed that for the number of cells from 32726 to 95128, mole fraction changed, however, for the number of cells more than 128636, no changes occurred in the mole fraction of outlet syngas. Thus, for simulating the reactor, a mean cell size of $0.75 \mathrm{~mm}$, which resulted in the total number of 128636 cells, was used for the entire geometry. Figure $2 \mathrm{~b}$ shows the generated mesh for the geometry with a mean cell size of $0.75 \mathrm{~mm}$.

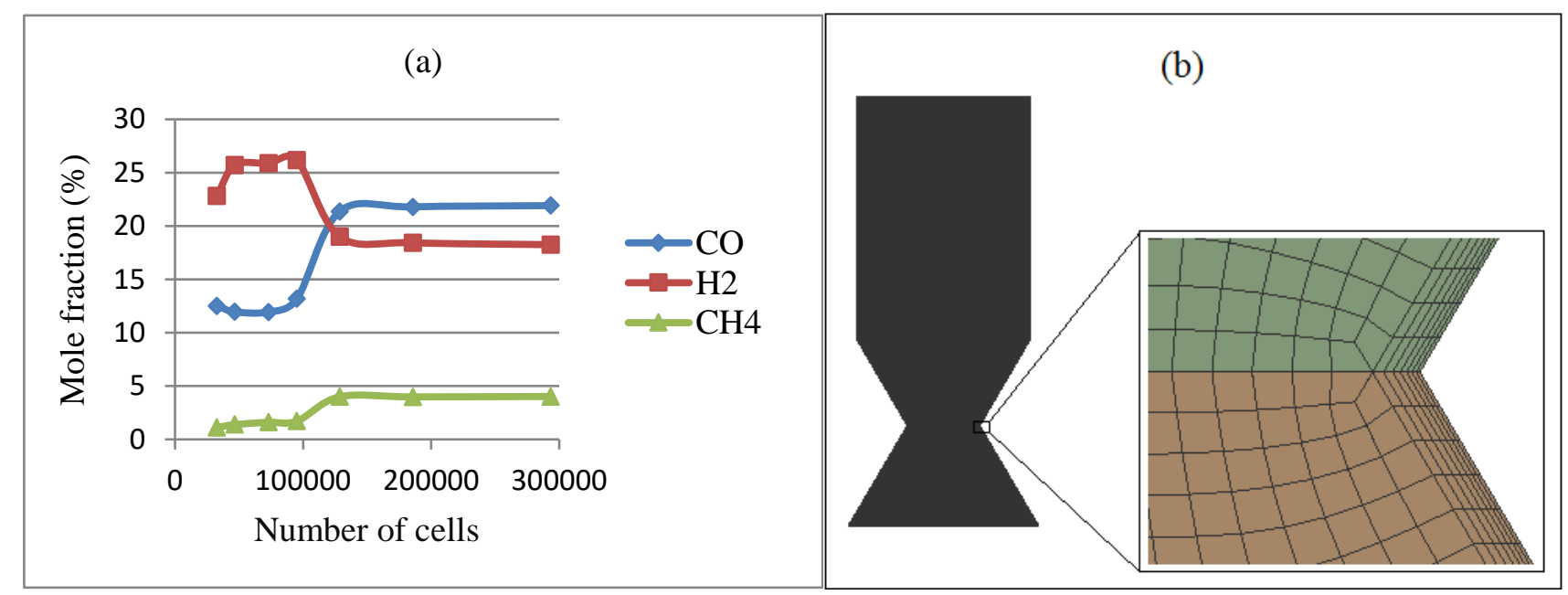

Figure 2. Grid study; (a) outlet syngas mole fraction for different cell numbers, (b) generated mesh

\section{Results and Discussion}

Investigated parameters included the inlet velocity of air-steam mixture, the preheating temperature of inlet air, the ratio of steam to air (S/A), and the moisture content of sugarcane bagasse. The base values of these parameters were assumed to be as follows: air velocity of $30 \mathrm{~m} / \mathrm{s}$, preheating temperature of $1300 \mathrm{~K}, \mathrm{~S} / \mathrm{A}$ of 0.67 , and bagasse moisture content of $1.14 \%$. In the following sections, each parameter was changed, and the results were evaluated. Outlet syngas mole fraction and conversion efficiency of the present study were in agreement with the experimental results of previous studies [23, 47, 55-57]. Table 2 represents a comparison of the results of the present study with the experimental data of the literature $[23,47,58,59]$. It is obvious that the results of outlet syngas mole fraction match well with the results of Anukam et al. [47] and Huang et al. [23]. The conversion efficiency of the downdraft fixed-bed gasifier has been reported to be $60-85 \%$ in most studies [55-57]. In the present study, the conversion efficiency of $64.6 \%$ was obtained for the base case, which was in good agreement with the experimental data shown in Table 2. Slight differences in the results were due to the variations in geometries, type of feedstock, moisture content of biomass, inlet velocity, and oxidizing agent mixture. 
Table 2 a comparison of the results of the present study with the experimental data of the previous studies $[23,47,59]$

\begin{tabular}{c|c|c|c|c|c|c}
\hline \multicolumn{5}{c|}{ Outlet syngas mole fraction } & \multicolumn{2}{c}{ Conversion efficiency } \\
\hline & CO & H2 & CH4 & N2 & Present study & $64.6 \%$ \\
\hline Present study & $21 \%$ & $19 \%$ & $3.9 \%$ & $43 \%$ & Anukam et al. & $50-65 \%$ \\
& & & & & & \\
\hline Anukam et al. & $20 \%$ & $17.5 \%$ & $2.5 \%$ & $46 \%$ & Basu et al. & $60-70 \%$ \\
& & & & & & \\
\hline Huang et al. & $18-25 \%$ & $15-24 \%$ & $0-3 \%$ & $43-52 \%$ & Gunarathne et al. & $72.6 \%$ \\
\hline
\end{tabular}

The mole fraction contours of outlet syngas are shown in Figure 3. These contours were obtained from the simulation of sugarcane bagasse gasification based on the values mentioned in the previous paragraph. It was seen that syngas concentration was about zero in the upper zone of the reactor. The reason was that tar formation reactions were neglected in the present study. As previously said, because our main objective was to observe the distribution of outlet syngas and conversion efficiency of the reactor in different operating conditions, so it was neglected because final tar is formed in a small amount and has little impact on syngas yield [49]. Consequently, in this region, there was a large amount of unconverted carbon, which would get reduced along the gasifier. In the second zone, partial oxidation reaction (Eq. 1) started to occur near the walls, thereby producing carbon monoxide. At the beginning of the third zone, oxidizing agent (air-steam mixture) entered the reactor, caused higher rates of gasification reactions. Similar contours of $\mathrm{H}_{2}$ and $\mathrm{CO}_{2}$, in the lower half of the gasifier, were caused by high rates of water-gas shift reaction (Eq. 6) in this region. Because of the feed of oxygen being insufficient for full combustion, some of the carbon was converted into $\mathrm{CO}$ and $\mathrm{H}_{2}$ by reacting with $\mathrm{H}_{2} \mathrm{O}$ and $\mathrm{CO}_{2}$ based on the reactions of Eq. (7) and (8). The molar fractions of $\mathrm{H}_{2}$ and $\mathrm{CO}_{2}$ were in their highest amount near the steam-air mixture nozzles. On the other hand, the molar fractions of $\mathrm{CO}$ and $\mathrm{CH}_{4}$ reach their highest amount at lower heights. At the bottom of the gasifier, the mole fractions of outlet syngas, $\mathrm{CO}, \mathrm{H}_{2}, \mathrm{CO}_{2}$ and $\mathrm{CH}_{4}$, were obtained equal to $21 \%, 19 \%, 10.4 \%$ and $3.9 \%$, respectively. 
(a) Mole fraction of $\mathrm{CO}$

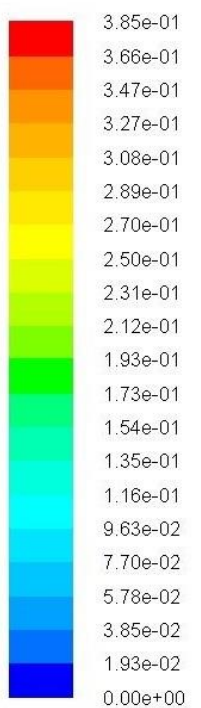

(b) Mole fraction of $\mathrm{h} 2$

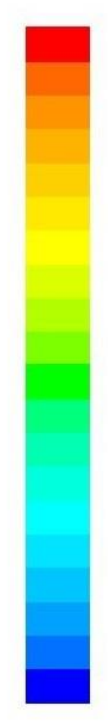

$.95 \mathrm{e}-01$

$3.36 \mathrm{e}-01$

3.16e-01

$2.97 e-01$

$2.77 \mathrm{e}-01$

$2.57 \mathrm{e}-01$

$2.37 e-01$

$2.17 \mathrm{e}-01$

$1.98 \mathrm{e}-01$

$1.78 \mathrm{e}-01$

$1.58 \mathrm{e}-01$

$1.38 \mathrm{e}-01$

1. $19 \mathrm{e}-01$

9.88e-02

$7.91 \mathrm{e}-02$

$5.93 e-02$

$3.95 \mathrm{e}-02$

$1.98 \mathrm{e}-02$

$0.00 \mathrm{e}+00$

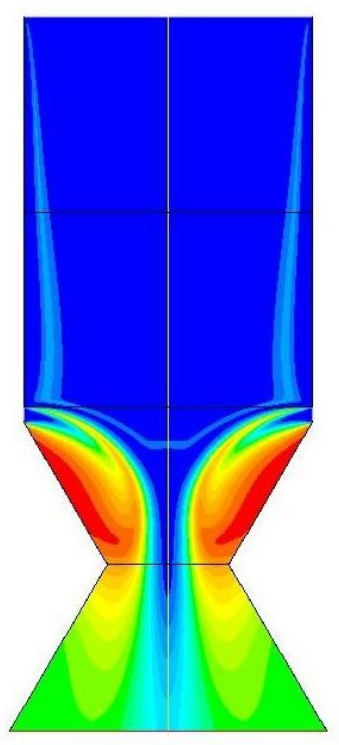

(d) Mole fraction of $\mathrm{CO} 2$

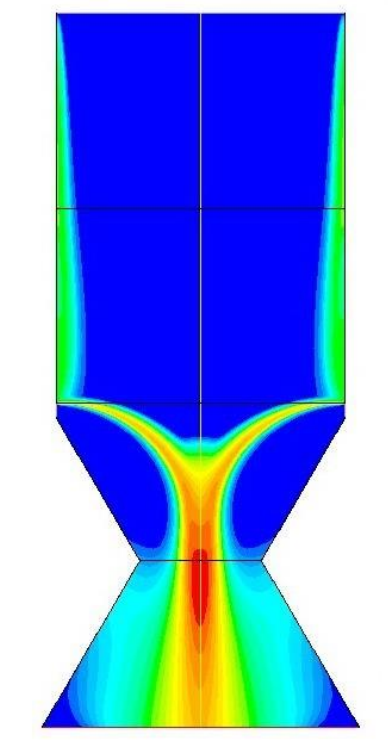

(c) Mole fraction of $\mathrm{Ch} 4$

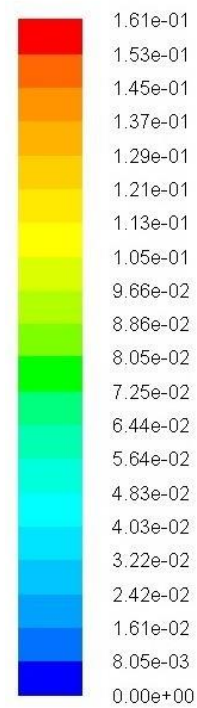

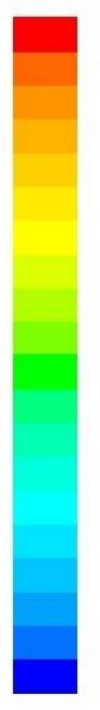
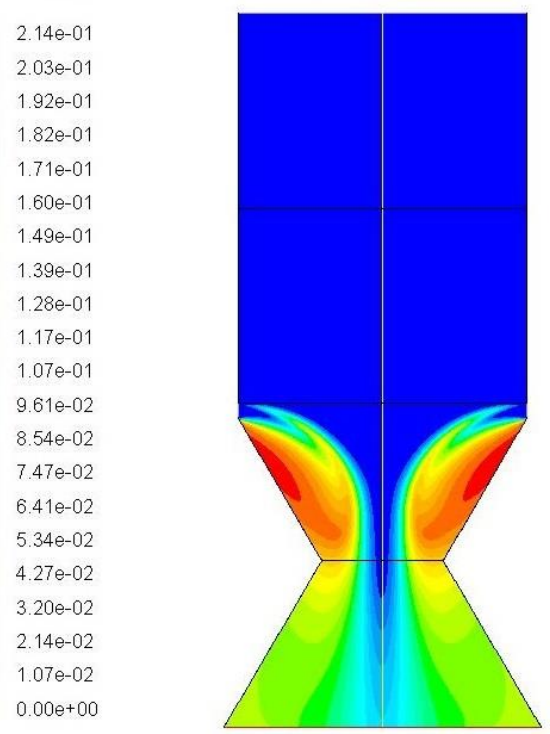

Figure 3. Contours of outlet syngas mole fraction: (a) $\mathrm{CO}$, (b) $\mathrm{H}_{2}$, (c) $\mathrm{CH}_{4}$ and (d) $\mathrm{CO}_{2}$

\subsection{Steam to air ratio (S/A)}

The mixture of air and steam was used as an oxidizing agent in the present study. The influence of different steam-to-air ratios (S/A) were studied by assuming that the velocity of mixture maintained constant. Figure 4a indicates the effect of S/A on the mole fraction of outlet syngas produced by sugarcane bagasse gasification. Five simulations were performed for different steam-to-air ratios of $0.11,0.25,0.43$ and 0.67 and 1 , while other effective parameters were assumed to be in their base case (air velocity of $30 \mathrm{~m} / \mathrm{s}$, preheating temperature of $1300 \mathrm{~K}$, and moisture content of $1.14 \%$ for 
bagasse). It was observed that by increasing S/A from 0.11 to 0.43 , the amount of CO increased from $19.9 \%$ to $21.8 \%$, while it started decreasing to $20.8 \%$ by increasing S/A to 1 . The mole fraction of $\mathrm{CO}_{2}$ steadily increased from $6.3 \%$ to $11.2 \%$. These results could be explained as water-gas-shift and steam-reforming reactions in Eq. (4) and (6). These reactions happened at higher rates in the presence of steam. For the mole fraction of $\mathrm{H}_{2}$, by increasing S/A from 0.11 to 1 , hydrogen gas steadily increased from $10 \%$ to $23 \%$. This could be explained as reactions of Eq. (4), (6) and (7) involved steam and might be favored by increasing the steam in the oxidizing agent. It was also observed that increasing S/A did not have a remarkable effect on $\mathrm{CH}_{4}$ mole fraction. The percentage of methane output varied between $3 \%-4 \%$.

To investigate the ratio of steam to air more precisely, the conversion efficiency of the gasification process was also calculated. Figure $4 \mathrm{~b}$ indicates the changes in the conversion efficiency of sugarcane bagasse gasification when S/A increases. It was obvious that by increasing S/A from 0.11 to 0.67 , conversion efficiency increased from $48.9 \%$ to $64.6 \%$, while it started to decrease to $63 \%$ by increasing this ratio to 1 . Thus, the optimum conversion efficiency was obtained equal to $68.6 \%$ in S/A of 0.67 , in which the molar fractions of outlet syngas were $21.4 \%, 19 \%, 4 \%$, and $10.4 \%$ for $\mathrm{CO}_{2}$, $\mathrm{H}_{2}, \mathrm{CH}_{4}$, and $\mathrm{CO}$ respectively. Therefore, increasing the steam-to-air ratio up to 0.67 had a positive influence on conversion efficiency and syngas yield, while an excessive increase in S/A could have adverse effects.

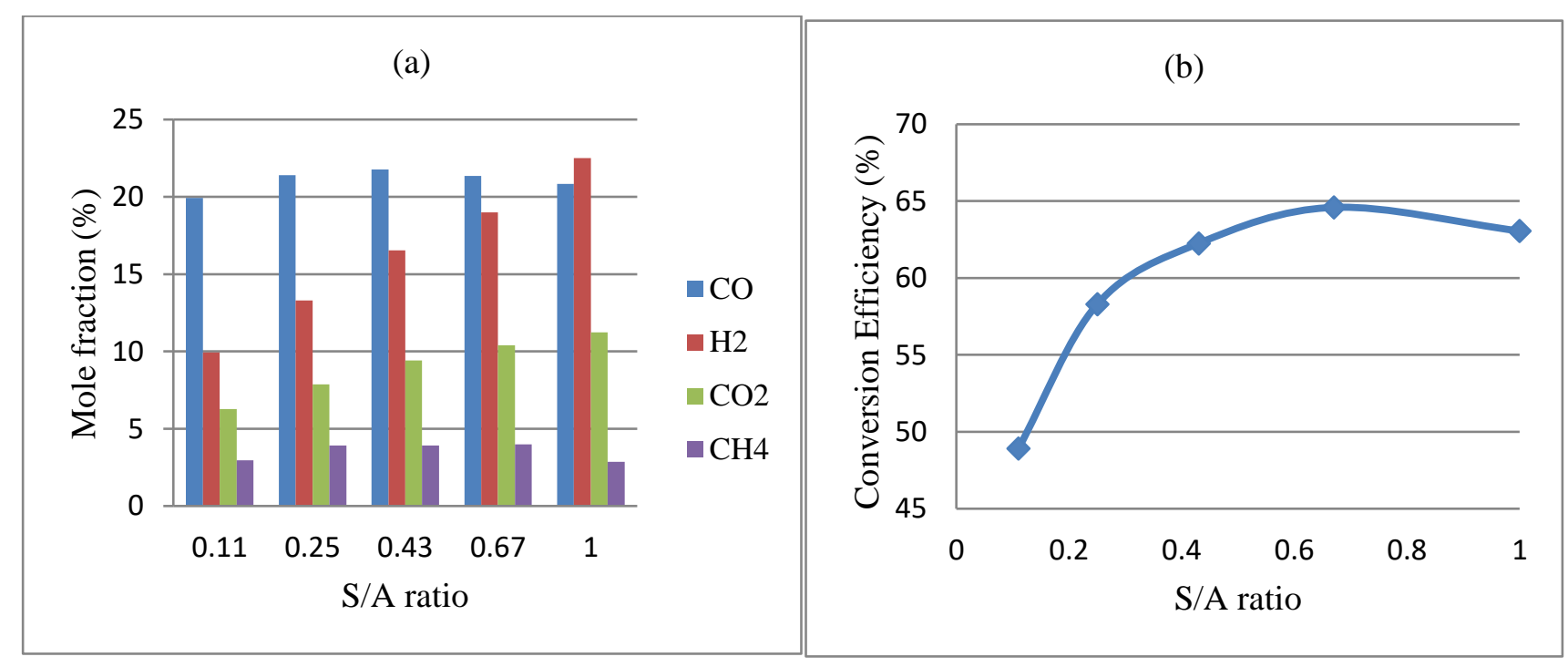

Figure 4. Effect of S/A on (a) the mole fraction of outlet syngas and (b) conversion efficiency

\subsection{Air-steam inlet velocity}

The inlet velocity of injected air-steam, passing through the nozzle, is a factor affecting the rate of reactions and the production of outlet syngas. Since dependent on the geometry of the reactor, it should be noted that the effect of the velocity parameter would vary according to the geometry. 
Therefore, the optimum velocity obtained for different geometries would be different from each other. For the reactor geometry of the present study, eight simulations were performed to look into the effect of air velocity on the gasification process. With $5 \mathrm{~m} / \mathrm{s}$ increment in each simulation, the air inlet velocity was changed from 5 to $40 \mathrm{~m} / \mathrm{s}$, while other parameters were maintained in their base values (preheating temperature of $1300 \mathrm{~K}, \mathrm{~S} / \mathrm{A}$ of 0.67 , and moisture content of $1.14 \%$ ). Figure 5a shows the effect of air inlet velocity on the mole fractions of outlet syngas during sugarcane bagasse gasification. With an increase in air inlet velocity from 5 to $20 \mathrm{~m} / \mathrm{s}$, the mole fraction of CO increased from $19.1 \%$ to $25 \%$, and then it decreased to $17.4 \%$ by increasing the velocity up to $40 \mathrm{~m} / \mathrm{s} . \mathrm{H}_{2}$ mole fraction fluctuated around $15 \%$ in the low values of air velocity, and then it went up to $23.4 \%$ with an increase in the air velocity to $40 \mathrm{~m} / \mathrm{s}$. The effect of air velocity on $\mathrm{CO}_{2}$ was the same as hydrogen gas. The results suggested that a noticeable variation in air velocity to large or small amounts could negatively affect the production of $\mathrm{CH}_{4}$.

To more precisely investigate the effect of air velocity, the conversion efficiency of the reactor was also calculated, and the effect of air inlet velocity was evaluated. Figure $5 \mathrm{~b}$ shows the effect of air inlet velocity on the conversion efficiency of the sugarcane bagasse gasification process. For the geometry of the present study, the optimum conversion efficiency was obtained equal to $68.4 \%$, which was achieved at the air inlet velocity of $20 \mathrm{~m} / \mathrm{s}$. Both decreasing and increasing the air inlet velocity had negative effects. By reducing the air inlet velocity to $5 \mathrm{~m} / \mathrm{s}$, conversion efficiency decreased to $50.5 \%$. This trend could be the result of lower rates of reactions when the air inlet velocity decreased. Increasing the air inlet velocity to $40 \mathrm{~m} / \mathrm{s}$ also reduced the quality of gasification and decreased the efficiency of gasification to $54.4 \%$. This could be because of decreased reaction residence time and a significant junction between injected air-steam from opposite nozzles. Generally, the optimal air inlet velocity depends on the geometry of the reactor, and it might be slightly diverse for different geometries in other studies.

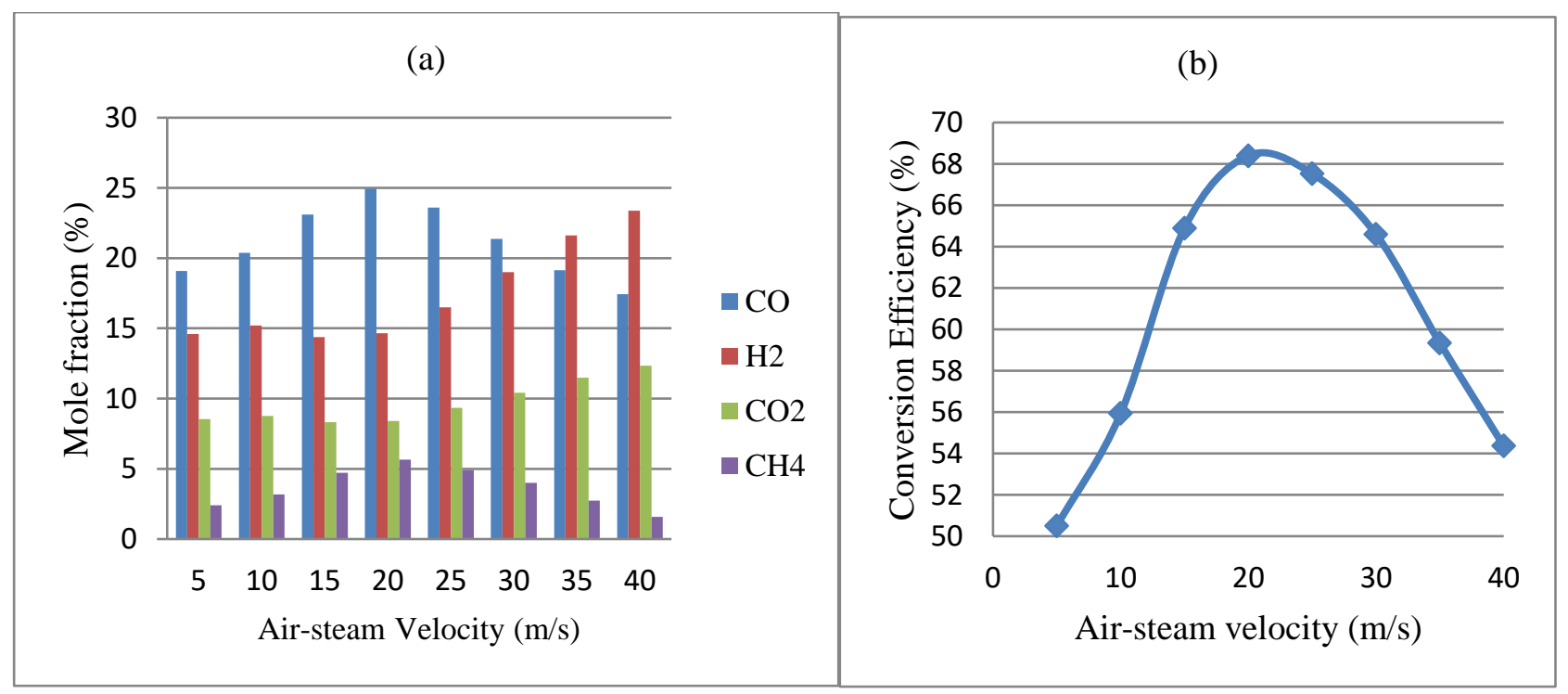

Figure 5. Effect of air-steam inlet velocity on (a) the mole fraction of outlet syngas and (b) conversion efficiency 


\subsection{Preheating temperature of inlet air-steam}

Gasification can be driven by partial oxidation without an external heat source; however, preheating the temperature of oxidizing agent can positively affect the conversion efficiency of the gasification process, although raising the air temperature to $1500 \mathrm{~K}$ or more is a challenge in real laboratory-scale operation. Practically, the energy required for preheating the temperature of the air entering reactor is prepared either by the heat transfer from the reactor itself or through a boiler as an external agent. In the present study, three simulations were performed for the air inlet temperatures of 1100,1300 , and $1500 \mathrm{~K}$ to investigate the variations of outlet syngas and conversion efficiency. Other parameters were assumed to be in their base case (air inlet velocity of $30 \mathrm{~m} / \mathrm{s}, \mathrm{S} / \mathrm{A}$ of 0.67 , and moisture content of $1.14 \%$ ). Figure $6 \mathrm{a}$ shows the effect of preheating temperature of inlet air on the mole fraction of outlet syngas. By increasing the air temperature from 1100 to $1500 \mathrm{~K}$, the mole fraction of carbon monoxide raised from $19.2 \%$ to $22.8 \%$, Moreover, the outlet content of $\mathrm{CH}_{4}$ increased from $2.7 \%$ to $4.6 \%$. This could be explained as higher chemical reaction rates in Eq. (1), (3) and (7). Conversely, preheating inlet air temperature had a negative effect on the mole fractions of $\mathrm{H}_{2}$ and $\mathrm{CO}_{2}$ gases. Mole fractions of hydrogen decreased from $21.2 \%$ to $17 \%$, and carbon dioxide decreased from $11.4 \%$ to $9.7 \%$. This could be explained as a water-gas-shift reaction (Eq. 6) is an exothermic reversible reaction [60]. Therefore, with increasing temperature, the rate of this reaction rate increases, but the conversion of reactants to products becomes less favorable.

To better assess the effect of preheating temperature, it was necessary to calculate the conversion efficiency of the gasification process. Figure $6 \mathrm{~b}$ shows the effect of preheating temperature of inlet air on the conversion efficiency of sugarcane bagasse gasification. It was obtained that the conversion efficiency of gasification increased from 58.8\% to $66.9 \%$ with an increase in preheating temperature from 1100 to $1500 \mathrm{~K}$. Therefore, preheating the inlet air-steam has a positive impact on gasification output, albeit impracticable to obtain extremely high preheating temperature in the real world, and also there might be a potential risk of coke formation at a higher temperature $[61,62]$ which can negatively influence the gas yield.

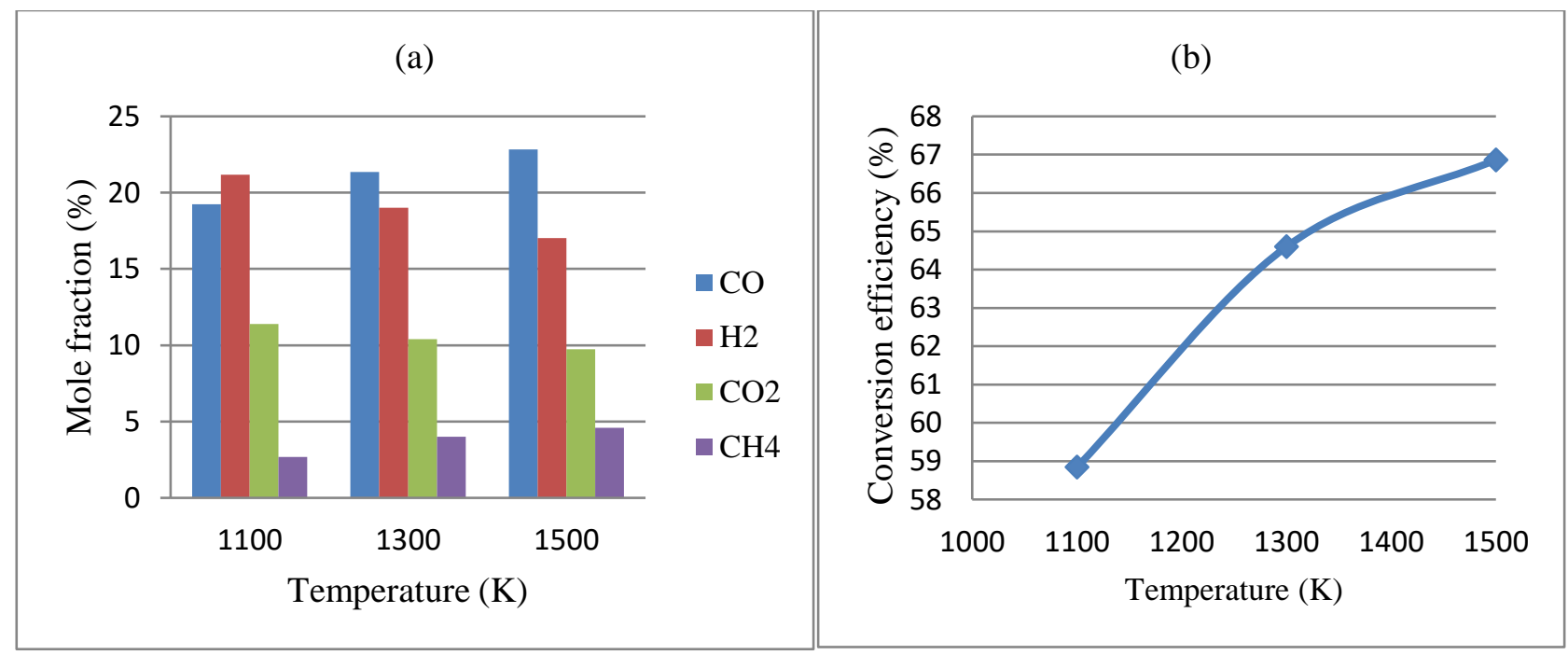


Figure 6. Effect of preheating temperature of inlet air on (a) the mole fraction of outlet syngas and (b) conversion efficiency

\subsection{Moisture content (MC) of sugarcane bagasse}

Sugarcane bagasse (or every other wood), used as fuel for the gasification process, initially contains a significant amount of moisture, which must be reduced for a more effective gasification process. In the present study, three simulations were carried out for the moisture contents of $1.14 \%$, $12 \%$, and $20 \%$, while other parameters were assumed in their base values (Air velocity of $30 \mathrm{~m} / \mathrm{s}$, preheating temperature of $1300 \mathrm{~K}$, and S/A of 0.67). The selection of these values for the proposed biomass feedstock was according to the actual values of sugarcane bagasse moisture content from three different sites that provided this material for our study. Figure 7a shows the effect of sugarcane bagasse moisture content on the mole fraction of outlet syngas. It was observed that increasing MC from $1.14 \%$ to $20 \%$ caused a reduction in the production of $\mathrm{CO}$, from $20.7 \%$ to $17.5 \%$. Conversely, increasing the $\mathrm{MC}$ was accompanied by an increase in the production of $\mathrm{H}_{2}$ and $\mathrm{CO}_{2}$. Outlet mole fraction of $\mathrm{H}_{2}$ increased from $19.3 \%$ to $20.8 \%$, and $\mathrm{CO}_{2}$ from $10.7 \%$ to $12.2 \%$. The reason for this trend was the higher rates of water-gas-shift and steam-reforming reactions (Eq. 6 and 4), which resulted in an increase in the production of hydrogen and carbon dioxide, and a decrease in the production of carbon dioxide. The effect of change in MC was not significant on the mole fraction of $\mathrm{CH}_{4}$ and it remained constant, about $4 \%$.

To better assess the effect of bagasse MC, it was necessary to calculate the conversion efficiency of the gasification process. Figure $7 \mathrm{~b}$ shows the effect of sugarcane bagasse moisture content on the conversion efficiency of gasification. By increasing MC from $1.14 \%$ to $20 \%$, conversion efficiency decreased from $64.6 \%$ to $61.4 \%$. It was concluded that high amounts of $\mathrm{MC}$ in biomass has a negative effect on the conversion efficiency of the gasification process. Factually reduction reactions, which take place in the reduction zone, produce the greatest amounts of syngas. Most of these reactions are endothermic. Therefore, if the moisture content of biomass is reduced, heat would not be consumed during the drying of biomass; consequently, it would be available for the reduction reactions to occur in higher rates. In addition, water production is expected in reality, which has not been taken into account herein for more simplification. A more detailed reaction network will be taken into consideration to improve upon the current simulation in the future. Clearly, the initial moisture content will reduce the organic material input to begin with, which is another cause of lower gas yields in the product stream. 


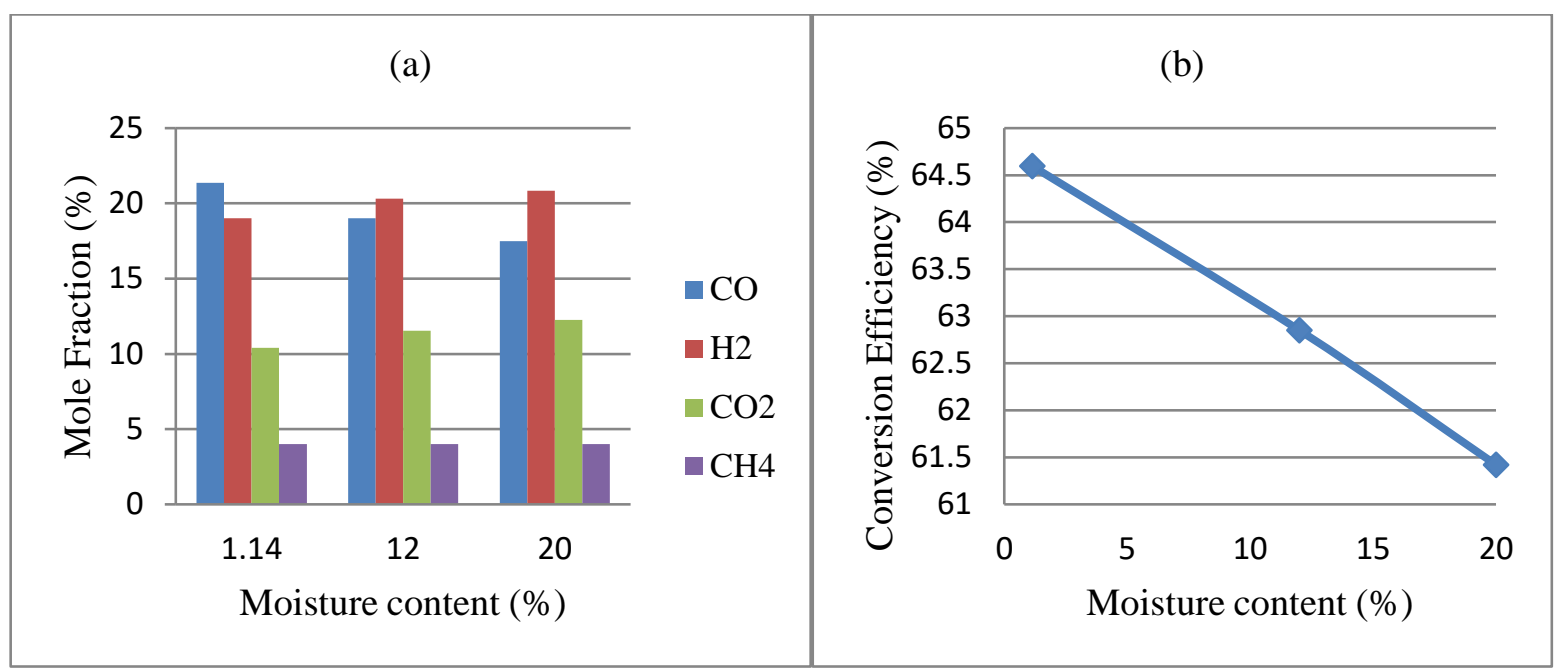

Figure 7. Effect of moisture content on (a) the mole fraction of outlet syngas and (b) conversion efficiency

\subsection{Optimum conditions}

Finally, another simulation was conducted to obtain the maximum values of outlet syngas and conversion efficiency. Optimal parameters (inlet velocity of $20 \mathrm{~m} / \mathrm{s}$, preheating temperature of 1500 $\mathrm{K}, \mathrm{S} / \mathrm{A}$ ratio of 0.67 and $\mathrm{MC}$ of 1.14) were applied for this simulation. It was found that for the optimum conditions, the mole fractions of carbon monoxide, hydrogen, methane, and carbon dioxide were $24.2 \%, 14.4 \%, 5.4 \%$, and $8.3 \%$, respectively. Moreover, the conversion efficiency of $69.14 \%$ was obtained in optimal operating conditions.

It is important to note that all estimated values by our simulation model were within $7-16 \%$ of the actual values determined by the experiment. A detailed report of our experimental work will be published later. This study provided a very effective tool to predict the outcome of complex gasification systems using a simplified array of the reaction network. Furthermore, the newly developed solution technique can potentially facilitate process design strategies in the field of renewable energy.

\section{Conclusion}

A two-dimensional CFD model of a downdraft fixed-bed gasifier was developed to study the simultaneous influences of operating parameters affecting the gasification process and to observe the final product distribution in different operation conditions. Sugarcane bagasse was employed as biomass for a gasification process, as there is an ample amount of it in our country, Iran, in hopes of being useful to engineers who want to make use of this waste material. The studied parameters were the steam-to-air ratio (S/A) of the oxidizing agent, the inlet velocity and preheating temperature of airsteam, and the moisture content of sugarcane bagasse. Several simulations were performed by assuming that one parameter was changing in each simulation, while other parameters were maintained in their base values. The results obtained from the present study were in good agreement 
with the experimental data of previous investigations. Outlet syngas mole fraction and conversion efficiency of the gasification process were reported as the results.

The results proposed that increasing S/A up to 0.67 had positive impacts on the quality of the gasification process and resulted in higher rates of reactions and conversion efficiency. While an excessive increase in S/A (more than 0.67 ) could have unfavorable effects and reduce the efficiency of gasification. Optimal air inlet velocity, which is dependent on the geometry of the simulated reactor, was obtained at a median amount (20 m/s in this study). Both lowering and increasing the air inlet velocity had negative influences on the gasification process. Preheating the inlet air resulted in higher conversion efficiency, although quite impracticable to obtain extremely high preheating temperature in the real world. Reducing the moisture content of sugarcane bagasse was also favorable. Instead of being consumed during the drying of biomass, heat would be available for reduction reactions (mostly endothermic), and raise the efficiency of the gasification process. Finally, another simulation was performed according to the optimal values obtained in each section. The mole fractions of carbon monoxide, hydrogen, methane, and carbon dioxide were obtained equal to $24.2 \%$, $14.4 \%, 5.4 \%$, and $8.3 \%$, respectively. In addition, a conversion efficiency of $69.14 \%$ was achieved in the optimal operating conditions.

\section{Conflict of interest}

The authors declare that there is no conflict of interest.

\section{References}

1. Hosseini, S.E., et al., A review on biomass-based hydrogen production for renewable energy supply. International Journal of Energy Research, 2015. 39(12): p. 1597-1615.

2. Jahromi, H., et al., Asphaltenes biodegradation under shaking and static conditions. Fuel, 2014. 117: p. 230-235.

3. Najafi, G., et al., Potential of bioethanol production from agricultural wastes in Iran. Renewable and Sustainable Energy Reviews, 2009. 13(6-7): p. 1418-1427.

4. Reddy, M.V., et al., Aerobic remediation of petroleum sludge through soil supplementation: microbial community analysis. Journal of hazardous materials, 2011. 197: p. 80-87.

5. Jahromi, H. and F.A. Agblevor, Upgrading of pinyon-juniper catalytic pyrolysis oil via hydrodeoxygenation. Energy, 2017. 141: p. 2186-2195.

6. Naqvi, S.R., Y. Uemura, and S.B. Yusup, Catalytic pyrolysis of paddy husk in a drop type pyrolyzer for bio-oil production: The role of temperature and catalyst. Journal of Analytical and Applied Pyrolysis, 2014. 106: p. 57-62.

7. Spitzley, D.V., G.A. Keoleian, and S.G. Baron, Life cycle energy and environmental analysis of a microgrid power pavilion. International Journal of Energy Research, 2007. 31(1): p. 1-13.

8. Agblevor, F.A. and H. Jahromi, Aqueous-phase synthesis of hydrocarbons from furfural reactions with low-molecular-weight biomass oxygenates. Energy \& Fuels, 2018. 32(8): p. 8552-8562.

9. Agblevor, F.A. and H. Jahromi, Aqueous phase synthesis of hydrocarbons from reactions of guaiacol and low molecular weight oxygenates. ChemCatChem, 2018. 10(22): p. 5201-5214.

10. Hakeem, K.R., M. Jawaid, and O.Y. Alothman, Agricultural biomass based potential materials. 2015: Springer. 
11. Huber, G.W., S. Iborra, and A. Corma, Synthesis of transportation fuels from biomass: chemistry, catalysts, and engineering. Chemical Reviews, 2006. 106(9): p. 4044-4098.

12. Jahromi, H. and F.A. Agblevor, Hydrotreating of guaiacol: A comparative study of Red mud-supported nickel and commercial Ni/SiO2-Al2O3 catalysts. Applied Catalysis A: General, 2018. 558: p. 109-121.

13. Nanda, S., et al., An assessment on the sustainability of lignocellulosic biomass for biorefining. Renewable and Sustainable Energy Reviews, 2015. 50: p. 925-941.

14. Saidur, R., et al., A review on biomass as a fuel for boilers. Renewable and sustainable energy reviews, 2011. 15(5): p. 2262-2289.

15. Karmee, S.K., W. Swanepoel, and S. Marx, Biofuel production from spent coffee grounds via lipase catalysis. Energy Sources, Part A: Recovery, Utilization, and Environmental Effects, 2018. 40(3): p. 294-300.

16. Kirubakaran, V., et al., A review on gasification of biomass. Renewable and Sustainable Energy Reviews, 2009. 13(1): p. 179-186.

17. Dhanavath, K.N., et al., Oxygen-steam gasification of karanja press seed cake: Fixed bed experiments, ASPEN Plus process model development and benchmarking with saw dust, rice husk and sunflower husk. Journal of Environmental Chemical Engineering, 2018. 6(2): p. 3061-3069.

18. Gagliano, A., et al., A robust numerical model for characterizing the syngas composition in a downdraft gasification process. Comptes Rendus Chimie, 2016. 19(4): p. 441-449.

19. Patra, T.K. and P.N. Sheth, Biomass gasification models for downdraft gasifier: A state-of-the-art review. Renewable and Sustainable Energy Reviews, 2015. 50: p. 583-593.

20. Chogani, A., A. Moosavi, and M. Rahiminejad, Numerical Simulation of Salt Water Passing Mechanism Through Nanoporous Single-Layer Graphene Membrane. Chemical Product and Process Modeling, 2016. 11(1): p. 73-76.

21. Li, Y., et al., Simulation of biomass gasification in a fluidized bed by artificial neural network (ANN). Energy Sources, Part A: Recovery, Utilization, and Environmental Effects, 2018. 40(5): p. 544-548.

22. Sharzehee, M., S.S. Khalafvand, and H.-C. Han, Fluid-structure interaction modeling of aneurysmal arteries under steady-state and pulsatile blood flow: A stability analysis. Computer methods in biomechanics and biomedical engineering, 2018. 21(3): p. 219-231.

23. Huang, H.-J. and S. Ramaswamy, Modeling biomass gasification using thermodynamic equilibrium approach. Applied biochemistry and biotechnology, 2009. 154(1-3): p. 14-25.

24. Jarungthammachote, S. and A. Dutta, Thermodynamic equilibrium model and second law analysis of a downdraft waste gasifier. Energy, 2007. 32(9): p. 1660-1669.

25. Melgar, A., et al., Thermochemical equilibrium modelling of a gasifying process. Energy conversion and management, 2007. 48(1): p. 59-67.

26. Sharma, A.K., Equilibrium modeling of global reduction reactions for a downdraft (biomass) gasifier. Energy Conversion and Management, 2008. 49(4): p. 832-842.

27. Zainal, Z., et al., Prediction of performance of a downdraft gasifier using equilibrium modeling for different biomass materials. Energy conversion and management, 2001. 42(12): p. 1499-1515.

28. Di Blasi, C., Dynamic behaviour of stratified downdraft gasifiers. Chemical engineering science, 2000. 55(15): p. 2931-2944.

29. Giltrap, D., R. McKibbin, and G. Barnes, A steady state model of gas-char reactions in a downdraft biomass gasifier. Solar Energy, 2003. 74(1): p. 85-91.

30. Sheth, P.N. and B. Babu. Modeling and simulation of downdraft biomass gasifier. in Proceedings of 2009 Annual Meeting of AIChE, Gaylord Opryland Hotel, Nashville, TN, USA. 2009.

31. Wang, Y. and C. Kinoshita, Kinetic model of biomass gasification. Solar Energy, 1993. 51(1): p. 19-25.

32. Chaurasia, A., Modeling of downdraft gasification process: Studies on particle geometries in thermally thick regime. Energy, 2018. 142: p. 991-1009.

33. Bogdanova, V., et al., Numerical CFD Simulations for Optimizing a Biomass Gasifier and Methanation Reactor Design and Operating Conditions. Energy Procedia, 2017. 120: p. 278-285. 
34. Fernando, N. and M. Narayana, A comprehensive two dimensional Computational Fluid Dynamics model for an updraft biomass gasifier. Renewable Energy, 2016. 99: p. 698-710.

35. Wu, Y., et al., Two-dimensional computational fluid dynamics simulation of biomass gasification in a downdraft fixed-bed gasifier with highly preheated air and steam. Energy \& Fuels, 2013. 27(6): p. 3274-3282.

36. Chogani, A., et al., The effect of chemical functional groups and salt concentration on performance of single-layer graphene membrane in water desalination process: A molecular dynamics simulation study. Journal of Molecular Liquids, 2020: p. 112478.

37. Jahromi, S., E. Amani, and S. Movahed, An improved hybrid continuum-atomistic four-way coupled model for electrokinetics in nanofluidics. Electrophoresis, 2019. 40(12-13): p. 1678-1690.

38. Iran Sugarcane Development Company, http://www.iran-sugar.com, 2018.

39. Sreejith, C., C. Muraleedharan, and P. Arun, Performance prediction of steam gasification of wood using an ASPEN PLUS thermodynamic equilibrium model. International journal of sustainable energy, 2014. 33(2): p. 416-434.

40. Muilenburg, M.A., Computational modeling of the combustion and gasification zones in a downdraft gasifier. 2011: The University of lowa.

41. Xue, Q., T. Heindel, and R. Fox, A CFD model for biomass fast pyrolysis in fluidized-bed reactors. Chemical Engineering Science, 2011. 66(11): p. 2440-2452.

42. Zhang, Q., et al., Eulerian model for municipal solid waste gasification in a fixed-bed plasma gasification melting reactor. Energy \& Fuels, 2011. 25(9): p. 4129-4137.

43. Gerun, L., et al., Numerical investigation of the partial oxidation in a two-stage downdraft gasifier. Fuel, 2008. 87(7): p. 1383-1393.

44. Muilenburg, M., Y. Shi, and A. Ratner. Computational modeling of the combustion and gasification zones in a downdraft gasifier. in ASME 2011 International Mechanical Engineering Congress and Exposition. 2011. American Society of Mechanical Engineers.

45. Akbarzadeh, A. and I. Borazjani, Reducing flow separation of an inclined plate via travelling waves. Journal of Fluid Mechanics, 2019. 880: p. 831-863.

46. Luan, Y.-T., Y.-P. Chyou, and T. Wang, Numerical analysis of gasification performance via finite-rate model in a cross-type two-stage gasifier. International Journal of Heat and Mass Transfer, 2013. 57(2): p. 558-566.

47. Anukam, A., et al., Computer simulation of the mass and energy balance during gasification of sugarcane bagasse. Journal of Energy, 2014. 2014.

48. Kumar, A., D.D. Jones, and M.A. Hanna, Thermochemical biomass gasification: a review of the current status of the technology. Energies, 2009. 2(3): p. 556-581.

49. Dutta, S.S.P.A., CFD analysis of biomass downdraft gasifier using fluent. International Journal of Innovation in Engineering Research and Management ISSN 2348-4918, ISO 2000-9001 certified, E, 2015. 2(6).

50. Launder, B. and D. Spalding, Lectures in mathematical models of turbulence, 1972. Academic Press, London, England.

51. Bjerketvedt, D., J.R. Bakke, and K. Van Wingerden, Gas explosion handbook. Journal of hazardous materials, 1997. 52(1): p. 1-150.

52. Fossum, M., R.V. Beyer, and I. Bioenergy, Co-combustion: Biomass fuel gas and natural gas. SINTEF Energy Research, Trondheim, 1998.

53. Mamphweli, N.S., Implementation of a 150KVA biomass gasifier system for community economic empowerment in South Africa. 2009, University of Fort Hare.

54. Stanmore, B., Generation of energy from sugarcane bagasse by thermal treatment. Waste and Biomass Valorization, 2010. 1(1): p. 77-89.

55. Basu, P., V. Mettanant, and A. Leon. Gasification of rice husk in supercritical water. in Proceedings of the 8th World Conference on Chemical Engineering, Montreal, August, Paper \#971. 2009. 
56. Gunarathne, D., et al., The Effect of Throat Diameter on the Performance a Downdraft Biomass Gasifier. International Journal of Energy Engineering, 2013. 3(3): p. 171-175.

57. Mamphweli, S., Physics 505 lecture notes. Unpublished lecture notes, University of Fort Hare, 2009.

58. Basu, P., V. Mettanant, and A. Leon. Gasification of rice husk in supercritical water. in Proceedings of the 8th World Conference on Chemical Engineering. 2009.

59. Gunarathne, D., et al., The effect of throat diameter on the performance of a downdraft biomass gasifier. International Journal of Energy Engineering, 2013(3): p. 171-175.

60. Ratnasamy, C. and J.P. Wagner, Water gas shift catalysis. Catalysis Reviews, 2009. 51(3): p. 325-440.

61. Jahromi, H. and F.A. Agblevor, Hydrodeoxygenation of pinyon-juniper catalytic pyrolysis oil using red mud-supported nickel catalysts. Applied Catalysis B: Environmental, 2018. 236: p. 1-12.

62. Jahromi, H. and F.A. Agblevor, Hydrodeoxygenation of aqueous-phase catalytic pyrolysis oil to liquid hydrocarbons using multifunctional nickel catalyst. Industrial \& Engineering Chemistry Research, 2018. 57(39): p. 13257-13268. 